\title{
Estratégias de manejo de coberturas de solo no inverno para cultivo do milho em sucessão no sistema semeadura direta
}

\author{
Management strategies of winter cover crops to maize grown in succession in no-till system
}

\author{
Paulo Regis Ferreira da Silva ${ }^{1}$ Gilber Argenta ${ }^{2}$ Luis Sangoi ${ }^{3}$ Mércio Luiz Strieder $^{4}$ \\ Adriano Alves da Silva ${ }^{5}$
}

\section{- REVISÃO BIBLIOGRÁFICA -}

\section{RESUMO}

A maioria dos produtores do estado do Rio Grande do Sul adota o sistema de semeadura direta, em que não há revolvimento do solo para preparo da área para semeadura. A adoção de um sistema de rotação e sucessão de culturas diversificado, que produza adequada quantidade de resíduos culturais na superfície do solo, é fundamental para sustentabilidade do sistema de semeadura direta. Os agricultores dispõem de várias espécies de cobertura de solo no inverno com potencial para anteceder a cultura do milho em sucessão. Na família das poáceas, destaca-se a aveia preta (Avena strigosa) como a mais cultivada. No entanto, o seu uso continuado pode causar prejuízos ao cultivo do milho em sucessão. Objetivando minimizar os efeitos das poáceas e ao mesmo tempo atender às exigências do sistema de semeadura direta, novas espécies de inverno pertencentes a famílias botânicas distintas, como fabáceas e brassicáceas, têm sido estudadas, tanto em cultivos solteiros quanto em consórcio com poáceas, como alternativas para anteceder o cultivo do milho. Assim, esta revisão bibliográfica tem como objetivos descrever as principais vantagens e limitações do uso de coberturas de solo no inverno, em cultivos solteiros ou consorciados, como culturas antecessoras ao milho no sistema de semeadura direta e discutir estratégias de manejo destas coberturas que resultem em maiores benefícios para o milho.
Palavras-chave: Zea mays, Avena strigosa, Vicia sativa, Raphanus sativus, plantio direto, consorciação de culturas, rendimento de grãos, adubação nitrogenada.

\section{ABSTRACT}

The no-tillage system is adopted by most of the farmers in Rio Grande do Sul, Southern Brazil. No-till system requires no ploughing and only a narrow and superficial band or slot is opened in the soil to allow sowing. The sustainability of this system is dependent on a diversified system of crop rotation and succession able to leave on the soil an adequate amount of crop residues. In Rio Grande do Sul black oat (Avena strigosa L.) is the most cultivated cover crop, in spite of fact that different cover crops are available to precede the maize crop. Both maize and black oat belong to the Poaceae family and the continuous use of black oat may bring some losses to maize in succession. Therefore, other winter cover crop species, belonging to other taxonomic families, such legumes and crucifers, have been studied as alternatives to the no-till system which includes maize as a cash crop in the summer. The objectives of this review are: i) to describe the main advantages and limitations of winter cover crops, cultivated in pure stands or mixtures and ii) to discuss cover crops

\footnotetext{
${ }^{1}$ Departamento de Plantas de Lavoura, Faculdade de Agronomia, Universidade Federal do Rio Grande do Sul (UFRGS), 90001-970, Porto Alegre, RS, Brasil. E-mail: paulo.silva@ufrgs.br. Autor para correspondência.

${ }^{2}$ Desenvolvimento de Produtos, Syngenta Seeds, Uberlândia, MG, Brasil.

${ }^{3}$ Departamento de Fitotecnia, Universidade de Desenvolvimento do Estado de Santa Catarina (UDESC), Lages, SC, Brasil.

${ }^{4}$ Programa de Pós-graduação em Fitotecnia, Faculdade de Agronomia, UFRGS, Porto Alegre, RS, Brasil.

${ }^{5}$ Curso de Agronomia, UFRGS, Porto Alegre, RS, Brasil.
} 
management strategies that most benefit the maize crop in succession.

Key words: Zea mays, Avena strigosa, Vicia sativa, Raphanus sativus, no-till, intercropped systems, grain yield, nitrogen fertilization.

\section{INTRODUÇÃO}

Mais de $80 \%$ dos produtores de grãos do estado do Rio Grande do Sul adotam o sistema de semeadura direta (FARIAS \& FERREIRA, 2000; EMBRAPA, 2005), em que não há revolvimento do solo para preparo da área para a semeadura. Esse sistema, iniciado há cerca de 30 anos e ampliado de forma mais efetiva nos últimos 15 a 20 anos, fundamenta-se na produção de grande quantidade de massa vegetal para cobertura de solo, na prevenção da erosão hídrica, na conservação e melhoria das características físicas, químicas e biológicas do solo e no aumento de sua capacidade de armazenamento de água. Atualmente, os sistemas predominantes no sul do Brasil incluem os cultivos de soja, principalmente, e de milho no verão, e de aveia preta, predominantemente, e de cereais e oleaginosas de estação fria no inverno. A seqüência, a periodicidade de uso e a adequação dessas culturas variam de produtor a produtor.

Para sustentabilidade do sistema de semeadura direta é fundamental a sua associação a um sistema de rotação e de sucessão de culturas diversificado, que produza adequada quantidade de resíduos culturais na superfície do solo. O seu uso objetiva não apenas uma mudança de espécies, mas sim a escolha de uma seqüência apropriada e de práticas culturais que atendam às suas necessidades e características nos aspectos edafo-climáticos e de ocorrência de plantas daninhas, de pragas e de moléstias. Entre as vantagens do uso de sistemas apropriados de rotação e de sucessão de culturas. destacam-se a estabilidade de rendimento de grãos, através da quebra do ciclo de pragas e de moléstias e da diminuição da infestação de plantas daninhas; a alternância no padrão de extração e de reciclagem de nutrientes com uso de espécies com diferentes sistemas radiculares e na manutenção ou na melhoria das condições físicas do solo (REGO, 1994). Considera-se que a condição ideal é aquela em que o solo tenha sempre uma espécie de planta se desenvolvendo, determinando alto fluxo de carbono e de energia no sistema solo-planta-atmosfera, para beneficiar as suas qualidades físicas, químicas e biológicas (VEZZANI, 2002).
Na região Sul do Brasil, os agricultores dispõem de várias espécies de cobertura de solo no inverno com potencial para participar de sistemas de sucessão com milho em semeadura direta. Entre os atributos sugeridos para as espécies de cobertura de solo no inverno, destacam-se: elevados rendimento de matéria seca e taxa de crescimento, resistência à temperatura baixa, não se transformar em planta invasora, ser de fácil manejo, ter sistema radicular vigoroso e profundo e elevada capacidade de reciclar nutrientes e ser de fácil produção de sementes (EMBRAPA, 2003). Entre as espécies da família das poáceas, destaca-se a aveia preta (Avena sativa) como a mais cultivada. No entanto, o uso continuado da sucessão aveia preta e milho pode causar prejuízos à cultura do milho. Este fato tem determinado a necessidade de se estudar outras espécies de inverno pertencentes a outras famílias botânicas, tais como fabáceas e brassicáceas, seja em cultivos solteiros ou consorciados.

O objetivo desta revisão bibliográfica é apresentar estratégias de manejo de espécies de cobertura de solo no inverno, em cultivos isolados ou consorciados, para maiores benefícios ao milho cultivado em sucessão no sistema de semeadura direta.

Vantagens e limitações do uso de espécies de cobertura de solo em cultivos isolados como culturas antecessoras ao milho

Para beneficiar o sistema de semeadura direta, as espécies de cobertura de solo no inverno devem proteger o solo e melhorar as suas características físicas, químicas e biológicas para a cultura subseqüente. Além disto, devem incrementar o suprimento de nitrogênio (N) e o rendimento de grãos. As principais características agronômicas das espécies que apresentam potencial de uso na região Sul do Brasil foram descritas por MONEGAT (1991), SANTOS \& REIS (2001) e BARNI et al. (2003). No entanto, pouca ênfase foi dada nestas publicações a estratégias de manejo das coberturas de inverno que beneficiem os cultivos subsequentes.

A aveia preta é a espécie mais cultivada como cobertura de inverno no Sul do Brasil, antecedendo aos cultivos de milho e de soja, em sistema de plantio direto. Entre as causas determinantes do seu intenso uso destacam-se: alto rendimento de matéria seca, facilidade de aquisição de sementes e de implantação, rusticidade, rapidez de formação de cobertura, decomposição lenta e ciclo adequado. Entre os 
benefícios de poáceas como a aveia preta para o sistema semeadura direta podem ser citados: melhoria das características físicas, químicas e biológicas do solo e eficiente proteção do solo pelos seus resíduos (MOODY et al., 1961; TISDALL \& OADES, 1982; BURLE et al., 1997; BOLINDER et al., 1999). No entanto, quando o milho é cultivado em sucessão à aveia preta, geralmente ocorre redução na absorção de $\mathrm{N}$ e no rendimento de grãos, devido à elevada relação carbono:nitrogênio $(\mathrm{C} / \mathrm{N})$ dos resíduos da aveia. Isto se deve ao processo de imobilização, devido a maior oferta de carbono ao sistema, que estimula a atividade microbiana (SÁ, 1996).

$A$ adição de quantidades elevadas de resíduos com elevada relação $\mathrm{C} / \mathrm{N}$ faz com que os organismos quimiorganotróficos, que atuam na decomposição da matéria orgânica, multipliquem-se gradativamente, produzindo $\mathrm{CO}_{2}$ em grande quantidade (VICTORIA et al., 1992). Além disto, a biomassa microbiana pode imobilizar, do início ao fim do ciclo do milho, alta quantidade de $\mathrm{N}$ mineral oriundo do solo e/ ou do N aplicado, especialmente no sistema semeadura direta (VARGAS et al., 2005). Desta forma, pode resultar em menor acúmulo de $\mathrm{N}$ na parte aérea do milho e, segundo VARGAS et al. (2005), a biomassa microbiana passa a atuar mais como agente de mineralização do $\mathrm{N}$ orgânico do solo do que como fonte de $\mathrm{N}$ potencialmente mineralizável, ainda mais quando houver elevado aporte de resíduos com alta relação C/ $\mathrm{N}$, como é os da aveia preta. Como conseqüência, o nitrato como o amônio presentes no solo praticamente desaparecem (VICTORIA et al., 1992). Além disto, a velocidade de liberação de $\mathrm{N}$ dos resíduos de aveia preta é lenta. Apenas 20\% do N contido na planta da aveia preta é disponibilizado nas primeiras quatro semanas após seu manejo (AMADO et al., 1999; AITA et al., 2001; AITA \& GIACOMINI, 2003). Isto promove assincronia entre a disponibilidade desse nutriente no solo e o desenvolvimento inicial da planta de milho. Para reduzir os efeitos prejudiciais dos resíduos culturais da aveia preta no milho cultivado em sucessão existem algumas estratégias de manejo que serão discutidas posteriormente.

As espécies da família fas Fabáceas de inverno possuem capacidade de fixar $\mathrm{N}$ atmosférico através da simbiose com bactérias específicas. Isto eleva a disponibilidade desse nutriente no solo, tornando as plantas desta família benéficas para anteceder a cultura do milho. Estima-se que $46 \mathrm{~kg}$ de $\mathrm{N}$ são acumulados por tonelada de matéria seca de parte aérea da ervilhaca comum (Vicia sativa) (BORKERT et al., 2003). Por sua vez, AMADO et al. (2002) estimam que a contribuição média de $\mathrm{N}$ da ervilhaca é de $120 \mathrm{~kg}$ $\mathrm{ha}^{-1}$, variando de 50 a $200 \mathrm{~kg} \mathrm{ha}^{-1}$. No entanto, devido à baixa relação $\mathrm{C} / \mathrm{N}$, a velocidade de liberação de $\mathrm{N}$ dos resíduos de fabáceas é muito rápida, quando comparada a outras espécies, tais como as poáceas. Estima-se que aproximadamente $60 \%$ do $\mathrm{N}$ da matéria seca da ervilhaca seja liberado durante os primeiros 30 dias após seu manejo (AMADO et al., 1999; AITA et al., 2001 eAITA \& GIACOMINI, 2003). Em função disto, recomenda-se que a semeadura do milho ocorra num período de tempo não superior a uma semana após o manejo (AITA et al., 2001; GIACOMINI et al., 2004). Outra vantagem do uso de fabáceas como cobertura de solo é a liberação mais lenta do $\mathrm{N}$ em relação aos adubos nitrogenados químicos, gerando menor risco de poluição ao ambiente.

Apesar destas vantagens, a intensidade de uso de fabáceas como espécies antecessoras ao milho no estado do Rio Grande do Sul é pequena, por apresentarem maior custo de implantação, menor rendimento de matéria seca e desenvolvimento inicial mais lento em relação às poáceas e, principalmente, pela rápida decomposição de seus resíduos. Além do crescimento inicial lento, o máximo acúmulo de matéria seca na ervilhaca nas condições do Sul do Brasil ocorre entre final de setembro e início de outubro. Por outro lado, a semeadura do milho nesta época é de alto risco, especialmente em regiões onde é freqüente a deficiência hídrica no período crítico deseu desenvolvimento do milho (duas semanas antes a duas semanas após o pendoamento). Em relação às fabáceas, a rápida decomposição dos resíduos culturais faz com que o solo fique desprotegido logo no início do desenvolvimento do milho, especialmente em áreas onde o sistema de semeadura direta encontra-se em fase inicial de implantação. Portanto, o desenvolvimento de práticas culturais que possibilitem maior tempo de permanência de resíduos de fabáceas na superfície do solo é importante para viabilizar o seu uso como cobertura de solo no inverno, conforme será visto mais adiante. Outro aspecto negativo do uso de fabáceas, tais como a ervilhaca comum, refere-se à elevada incidência de percevejos (Nezara viridula) e de lagarta rosca (Agrotis ipsilon). Este fato tem sido, em muitos casos, fator decisivo para não utilizar ervilhaca antecedendo a cultura do milho no Rio Grande do Sul, por afetar o principal componente do rendimento, o número de plantas por metro quadrado.

Existem ainda outras opções para cobertura de solo, tais como as espécies da família das brassicáceas, especialmente o nabo forrageiro (Raphanus sativus). Embora estas espécies não possuam a capacidade de fixar $\mathrm{N}$, elas apresentam alta 
capacidade de extrair este nutriente de camadas mais profundas do solo. Outras vantagens de seu uso são o desenvolvimento inicial muito rápido, alto rendimento de matéria seca e ciclo curto, o que viabiliza a semeadura precoce da cultura do milho em sucessão (meses de agosto e setembro). A possibilidade de semeadura precoce do milho é importante em regiões ecoclimáticas em que há grande probabilidade de ocorrência de deficiência hídrica nos meses de dezembro e janeiro, coincidindo com o período mais crítico da cultura, que compreende a fase de pendoamento até 30 dias após (MATZENAUER et al., 2002). Altos rendimentos de matéria seca da parte aérea de nabo (variando de 4,7 a 5,4t ha-1) têm sido obtidos na região ecoclimática da Depressão Central do estado do Rio Grande do Sul, em ensaios com essa espécie como cultura antecessora ao milho (FORSTHOFER et al., 2003; SUHRE et al., 2004). No entanto, assim como ocorre com as fabáceas, uma das grandes limitações do nabo forrageiro é a baixa relação $\mathrm{C} / \mathrm{N}$ dos resíduos, o que determina a rápida taxa de decomposição. Além disto, se mal manejado, ele pode se transformar em planta daninha importante para os cultivos subseqüentes. Outro aspecto negativo do uso do nabo forrageiro refere-se também à alta incidência de lagarta rosca.

Além dos aspectos já relatados sobre o uso de espécies de cobertura de solo no inverno, recentemente elas também têm recebido atenção especial em função da possível lixiviação de compostos orgânicos hidrossolúveis de seus resíduos, que são ácidos orgânicos de baixo peso molecular (FRANCHINI et al., 2001). Por sua vez, BAYER \& AMARAL (2003) constataram, num Latossolo Vermelho distrófico típico, que extratos aquosos de aveia preta e de nabo forrageiro reduzirem a acidez da camada superficial do solo e melhoram as condições do ambiente do solo para desenvolvimento das culturas de estação estival em sucessão.

Mesmo com todos os benefícios advindos do uso de espécies de cobertura de solo no inverno, seja em cultivos solteiros ou consorciados, o seu uso representa um investimento cujo retorno econômico ocorre apenas nos cultivos subseqüentes de verão. Assim, também é importante a busca de sistemas de produção que envolvam espécies de inverno de duplo propósito, que produzam resíduos culturais para o sistema semeadura direta e também grãos e/ou sementes. Desta forma, estar-se-á agregando valor aos cultivos de inverno e, conseqüentemente, aumentando a rentabilidade da atividade agrícola, com retorno mais rápido do investimento realizado. Entre os sistemas envolvendo culturas de inverno com duplo propósito passíveis de utilização, destacam-se a aveia preta, a ervilhaca comum e o nabo forrageiro para produção de sementes, ou de espécies tais como cereais e oleaginosas de estação fria para produção de grãos ou sementes. Porém, existirá a desvantagem do deslocamento da época de semeadura do milho para final de outubro ou início de novembro. Em regiões com deficiência hídrica, sem irrigação suplementar, esta época de semeadura poderá limitar muito a produtividade do milho (FORSTHOFER, 2004; REUNIÃO TÉCNICA..., 2005). Além disto, alguns destes sistemas poderão envolver a sucessão de duas espécies da família das poáceas, o que apresenta algumas desvantagens.

Sistemas consorciados de espécies de cobertura de solo de inverno para anteceder o cultivo do milho

Cada espécie cultivada como cobertura de solo no inverno apresenta vantagens e desvantagens para o milho em sucessão e para o sistema semeadura direta quando cultivada isoladamente, tornando difícil a recomendação de uma espécie que reúna somente aspectos desejáveis. O uso de sistemas consorciados de culturas pode formar camadas de coberturas de solo mais próximas do ideal, com benefícios para o rendimento de grãos do milho e para o sistema semeadura direta. Os sistemas consorciados podem propiciar eficiente cobertura vegetal no solo e maior reciclagem de nutrientes, principalmente de $\mathrm{N}$, no caso de fabáceas e brassicáceas.

O uso do consórcio entre espécies poáceas (aveia preta) e fabáceas (ervilhaca comum) diminui a necessidade de investir recursos financeiros na adubação nitrogenada em cobertura no milho em sucessão, sem reduzir o rendimento de matéria seca total da cobertura de solo em relação ao cultivo isolado de aveia preta (BORTOLINI et al., 2000). Neste mesmo estudo, estes autores verificaram que as vantagens do uso da ervilhaca comum isolada como cobertura de solo para fornecer $\mathrm{N}$ não se manifestaram com aplicação de altas doses de $\mathrm{N}$ na cultura do milho cultivada em sucessão ao consórcio aveia preta e ervilhaca comum. Com relação à proporção de sementes das espécies, verifica-se que, à medida que aumenta a proporção de sementes de ervilhaca comum no consórcio com aveia preta, aumenta a quantidade de $\mathrm{N}$ acumulada na planta e o rendimento de grãos de milho, especialmente quando cultivado sob doses baixas de N (BORTOLINI et al., 2000). A grande limitação do uso deste sistema de consórcio é que o rendimento de matéria seca da ervilhaca comum é potencializado nas condições do Rio Grande do Sul somente no final de setembro e no 
início de outubro, o que inviabiliza a semeadura precoce (agosto) de milho em sucessão, o que é vantajosa em determinadas regiões do Estado (FORSTHOFER, 2004; REUNIÃOTÉCNICA..., 2005).

Outro sistema de consórcio com potencial de uso durante o inverno é o que mescla uma espécie poácea (aveia preta) e uma brassicácea (nabo forrageiro) como culturas antecessoras ao milho. Este sistema de consórcio tem como vantagem a possibilidade da semeadura precoce do milho (agosto), devido ao ciclo curto das duas espécies. Além disto, tem-se observado
(Tabela 1) que o rendimento de grãos de milho em sucessão ao consórcio aumenta em relação ao obtido em sucessão à aveia preta em cultivo isolado, sem reduzir a produção de resíduos culturais para o sistema semeadura direta (SUHRE et al., 2004). Devido à baixa relação C/N dos resíduos culturais do nabo forrageiro, o rendimento de grãos de milho em sucessão é incrementado à medida que aumenta a proporção de sementes de nabo forrageiro nos sistemas consorciados com aveia preta. Nos sistemas consorciados entre aveia preta e nabo forrageiro, esta última é a espécie dominadora (Tabela 1). Este fato é

Tabela 1 - Rendimento de matéria seca de três espécies de cobertura de solo no inverno, em cultivos solteiros e consorciados, e rendimento de grãos de milho cultivado em sucessão, sob dois níveis de aplicação de nitrogênio (N). Eldorado do Sul-RS, $2001 / 2002$.

\begin{tabular}{|c|c|c|c|c|}
\hline \multirow{2}{*}{ Sistemas de cobertura de solo no inverno ${ }^{1 /}$} & \multicolumn{4}{|c|}{ Rendimento de matéria seca $\left(\mathrm{t} \mathrm{ha}^{-1}\right)$} \\
\hline & Aveia preta & Ervilhaca & Nabo & Total \\
\hline \multicolumn{5}{|l|}{ Pousio capinado } \\
\hline Aveia preta (100\%) & - & - & - & $3,6 \mathrm{bc} *$ \\
\hline Ervilhaca comum (100\%) & - & - & - & 2,9c \\
\hline Nabo forrageiro (100\%) & - & - & - & $5,9 a$ \\
\hline Aveia (50\%) + ervilhaca (50\%) & A $1,6 a$ & A $1,5 a$ & - & $3,1 \mathrm{c}$ \\
\hline Aveia $(50 \%)+$ nabo (50\%) & B $1,5 b$ & - & A $3,2 a$ & $4,7 \mathrm{ab}$ \\
\hline Ervilhaca (50\%) + nabo (50\%) & - & B 0,3b & A 2,9a & $3,2 \mathrm{c}$ \\
\hline \multirow[t]{3}{*}{ Aveia (34\%) + ervilhaca (33\%) + nabo (33\%) } & $\mathrm{AB} 1,2 \mathrm{~b}$ & B $0,7 b$ & A $1,7 \mathrm{ab}$ & $3,6 \mathrm{bc}$ \\
\hline & \multicolumn{4}{|c|}{ Rendimento de grãos $\left(\mathrm{t} \mathrm{ha} \mathrm{a}^{-1}\right)$} \\
\hline & \multicolumn{2}{|c|}{ Sem $N$} & \multicolumn{2}{|c|}{ Com N (180 kg ha $\left.{ }^{-1}\right)$} \\
\hline Pousio capinado & \multicolumn{2}{|c|}{$7,2 \mathrm{ab} *$} & \multicolumn{2}{|c|}{$12,8 b$} \\
\hline Aveia preta (100\%) & \multicolumn{2}{|c|}{$4,0 \mathrm{c}$} & \multicolumn{2}{|c|}{$12,6 b$} \\
\hline Ervilhaca comum (100\%) & \multicolumn{2}{|c|}{$8,2 \mathrm{a}$} & \multicolumn{2}{|c|}{$14,4 a$} \\
\hline Nabo forrageiro (100\%) & \multicolumn{2}{|c|}{$7,9 a$} & \multicolumn{2}{|c|}{$12,4 \mathrm{~b}$} \\
\hline Aveia (50\%) + ervilhaca (50\%) & \multicolumn{2}{|c|}{$5,5 \mathrm{bc}$} & \multicolumn{2}{|c|}{$12,2 b$} \\
\hline Aveia (50\%) + nabo (50\%) & \multicolumn{2}{|c|}{ 7,4ab } & \multicolumn{2}{|c|}{$12,9 b$} \\
\hline Ervilhaca (50\%) + nabo (50\%) & \multicolumn{2}{|c|}{ 7,3ab } & \multicolumn{2}{|c|}{$12,0 \mathrm{~b}$} \\
\hline Aveia (34\%) + ervilhaca (33\%) + nabo (33\%) & \multicolumn{2}{|c|}{ 7,2ab } & \multicolumn{2}{|c|}{$12,7 b$} \\
\hline
\end{tabular}

\footnotetext{
${ }^{1 /}$ Os valores percentuais se referem às quantidades de 100, 80 e $12 \mathrm{~kg} \mathrm{ha}^{-1}$ de sementes utilizadas na semeadura, em cultivos isolados de aveia preta, ervilhaca comum e de nabo forrageiro, respectivamente; * Na coluna, médias seguidas pela mesma letra minúscula e, nas, linhas médias seguidas pela mesma letra maiúscula não diferem significativamente entre si pelo teste de Duncan $(\mathrm{p}<0,05)$.
}

Fonte: SUHRE et al. (2004).

Ciência Rural, v.36, n.3, mai-jun, 2006. 
importante para determinar-se a proporção mais adequada de sementes dessas espécies no consórcio. Resultados experimentais obtidos por ARGENTA et al. (2002) na Depressão Central e na Serra Gaúcha e por SUHRE et al. (2004) na Depressão Central, evidenciam que o consórcio de ervilhaca comum ou de nabo forrageiro com aveia preta é uma das estratégias que podem ser usadas para minimizar o efeito prejudicial que essa espécie exerce no rendimento de grãos do milho em sucessão. Para escolha da espécie de cobertura mais adequada para anteceder o milho, seja em cultivo solteiro ou consorciado, alguns fatores devem ser observados: adaptação da espécie às condições edafoclimáticas da região, tempo de adoção do sistema semeadura direta, época de semeadura recomendada para o milho, grau de convicção do produtor na adoção do sistema semeadura direta e interesse e disponibilidade de capital do produtor para investimento.

Estratégias para reduzir os efeitos prejudiciais de espécies poáceas como cobertura de solo no inverno na cultura do milho em sucessão

Para minimizar a redução que se verifica no rendimento de grãos de milho em sucessão à aveia preta, decorrente da menor disponibilidade de $\mathrm{N}$ no solo durante o início do seu desenvolvimento, algumas alternativas de manejo vêm sendo estudadas. Além do uso de sistemas de consórcio com espécies com baixa relação $\mathrm{C} / \mathrm{N}$, destacam-se o aumento do nível de $\mathrm{N}$ mineral a ser aplicado na semeadura do milho, o atraso da época de semeadura do milho após a dessecação da aveia preta, a aplicação de $\mathrm{N}$ mineral em pré-semeadura do milho e o tipo de manejo dos resíduos culturais da aveia preta (mecânico ou químico). Todas estas estratégias têm como objetivo principal aumentar a taxa de decomposição de resíduos da aveia preta e diminuir o período de imobilização do N pelos microorganismos quimiorganotróficos (VICTORIA et al., 1992) na decomposição de sua palhada, aumentando a disponibilidade de $\mathrm{N}$ às culturas em sucessão.

Um dos primeiros trabalhos desenvolvidos em área sob sistema semeadura direta, objetivando diminuir o efeito negativo provocado pela alta relação C/N de resíduos de poáceas, foi o realizado por SÁ (1989) no Paraná. Ao avaliar o rendimento de grãos de milho à adubação nitrogenada em sucessão à aveia preta, este autor observou que a aplicação de até 30kg $\mathrm{ha}^{-1}$ de $\mathrm{N}$ na semeadura supre as necessidades iniciais da cultura, pois reduz parte do efeito prejudicial da elevada relação $\mathrm{C} / \mathrm{N}$ da aveia, através da maior decomposição dos seus resíduos e da maior liberação de $\mathrm{N}$ no período de maior demanda do milho. Contudo, em trabalhos posteriores SÁ, (1996) observou que em situações onde o sistema de semeadura direta está sendo implantado (menos de quatro anos), os níveis de $\mathrm{N}$ necessários na semeadura podem ser maiores, pois há elevado aporte de resíduos culturais de alta relação $\mathrm{C} / \mathrm{N}$. Após esta fase inicial de elevada imobilização de $\mathrm{N}$ e, portanto, de menor disponibilidade às plantas, inicia-se o restabelecimento do equilíbrio entre imobilização e mineralização, à medida que o aporte de resíduos culturais proporcionar acúmulo de $\mathrm{N}$ orgânico na camada superficial. Após nove a 12 anos de adoção do sistema semeadura direta, ocorre maior liberação de $\mathrm{N}$ para o sistema, diminuindo a resposta das culturas em sucessão à adubação nitrogenada (SÁ, 1996).

Em estudos conduzidos por ARGENTA et al. (1999) na Depressão Central do estado do Rio Grande do Sul, foi verificado que o aumento da dose de $\mathrm{N}$ mineral aplicado na semeadura do milho de 0 para $30 \mathrm{~kg}$ $\mathrm{ha}^{-1}$, em sistema semeadura direta e após aveia preta, também é alternativa eficiente para suprir as demandas iniciais, especialmente em solos mais arenosos e com menor teor de matéria orgânica, conforme observado na tabela 2. Entretanto, estes autores não observaram

Tabela 2 - Épocas e doses de aplicação de nitrogênio (N) e atraso na época de semeadura do milho após a dessecação da aveia preta como estratégias para reduzir os efeitos prejudiciais desta, em Eldorado do Sul-RS e Passo Fundo-RS, 1999/2000.

\begin{tabular}{|c|c|c|c|}
\hline \multicolumn{2}{|c|}{$\begin{array}{l}\text { Época e dose de } \mathrm{N} \\
\text { aplicado }\left(\mathrm{kg} \mathrm{ha}^{-1}\right)\end{array}$} & \multicolumn{2}{|c|}{ Local de avaliação } \\
\hline \multirow[t]{2}{*}{ Semeadura } & Cobertura & Eldorado do Sul & Passo Fundo \\
\hline & & \multicolumn{2}{|c|}{ Rendimento de grãos ( $\mathrm{t} \mathrm{ha}^{-1}$ ) } \\
\hline 0 & 0 & $2,8 c^{*}$ & $5,0 \mathrm{~b}$ \\
\hline 0 & 160 & $6,5 \mathrm{~b}$ & 9,3 a \\
\hline 30 & 130 & 7,8 a & 8,9 a \\
\hline 60 & 100 & 7,8 a & 9,1 a \\
\hline \multicolumn{2}{|c|}{$\begin{array}{l}\text { Época de semeadura } \\
\text { (dias após dessecação) }\end{array}$} & Eldorado do Sul & Passo Fundo \\
\hline & & \multicolumn{2}{|c|}{ Rendimento de grãos (t ha-1) } \\
\hline \multicolumn{2}{|l|}{1} & $5,3 \mathrm{~b}$ & 8,0 a \\
\hline \multicolumn{2}{|l|}{20} & $7,1 \mathrm{a}$ & 8,1 a \\
\hline
\end{tabular}
* Médias seguidas pela mesma letra na coluna não diferem
significativamente pelo teste Duncan $(\mathrm{p}<0,05)$.

Fonte: ARGENTA et al. (1999) 
incrementos no rendimento do milho com o uso de uma dose maior $\left(60 \mathrm{~kg} \mathrm{ha}^{-1}\right)$, diferentemente de SÁ (1989). Em solos mais arenosos e com menor teor de matéria orgânica, o atraso da semeadura do milho em 20 dias após dessecação da aveia preta (tabela 2) também evidenciou ser uma prática eficiente para diminuir a competição entre a planta de milho e os microorganismos do solo (ARGENTA et al., 1999). Por outro lado, estes autores também verificaram que, em situação de solos mais argilosos e com maior teor de matéria orgânica, não houve resposta do rendimento de grãos de milho ao atraso na dessecação da aveia preta.

A aplicação de $\mathrm{N}$ em pré-semeadura do milho, ou seja, durante o desenvolvimento vegetativo ou na dessecação da cultura antecedente, como, por exemplo, da a aveia preta, é outra estratégia existente que pode diminuir a deficiência de $\mathrm{N}$ no início de desenvolvimento da planta de milho. A maior disponibilidade de $\mathrm{N}$ mineral para a biomassa microbiana permitiria um fluxo mais contínuo de $\mathrm{N}$ no solo pelo processo de mineralização, resultando em maior disponibilidade para o milho (SÁ, 1996). Contudo, diversos trabalhos de pesquisa (SÁ, 1996; CERETTA et al., 2002) têm verificado que a eficiência desta técnica é muito dependente do regime hídrico vigente durante a estação de crescimento da espécie antecessora e do milho, havendo pouca diferença entre as épocas de aplicação de N. Em situações com elevada precipitação pluvial, os rendimentos de grãos de milho são maiores quando o N é aplicado parte na semeadura e o restante em cobertura, conforme trabalhos conduzidos por PÖTTKER \& WIETHÖLTER (2004), durante cinco estações de crescimento, e por BORTOLINI et al. (2001). Segundo estes autores, em situações com baixa precipitação pluvial, não se observam diferenças significativas entre a aplicação antecipada de $\mathrm{N}$ e a realizada em cobertura. No entanto, em situações de elevada precipitação pluvial durante a estação de crescimento do milho, geralmente, a aplicação antecipada de $\mathrm{N}$ reduz o rendimento de grãos em relação à aplicação com parte do $\mathrm{N}$ na semeadura e o restante em cobertura.

Outra técnica que pode afetar a taxa de decomposição da palha de aveia preta é o tipo de manejo adotado, seja de forma mecânica ou química. Resultados obtidos por ARGENTA et al. (2001) evidenciaram que tanto a forma de manejo de resíduos da aveia preta (não rolada, rolada ou roçada) e o tipo de herbicida não-seletivo usado na dessecação, seja ele de ação sistêmica (glyphosate) ou de ação de contato (glufosinate e paraquat), não afetaram o rendimento de grãos de milho em sucessão. No entanto, este estudo mostrou que a rolagem da palha da aveia preta foi mais eficiente em prevenir o estabelecimento de infestação de plantas daninhas, especialmente do capim papuã (Brachiaria plantaginea), do que a sua manutenção na forma em pé (não rolada e não roçada).

Estratégias para aumentar os benefícios do uso de fabáceas e brassicáceas como coberturas de solo no inverno no milho em sucessão

O atraso ou a não realização da dessecação da cobertura de inverno com herbicida não seletivo são duas práticas de manejo que podem aumentar o tempo de permanência de resíduos de fabáceas na superfície do solo, resultando em maior sincronismo entre a liberação de $\mathrm{N}$ de seus resíduos e o seu período de maior demanda pela planta. Além disto, estes tipos de manejo podem aumentar o rendimento de matéria seca da ervilhaca comum, por mantê-la vegetando por um período de tempo mais longo do que no sistema de manejo convencional (dessecação aos 15 a 20 dias antes da semeadura do milho). Assim, o atraso na morte da planta de ervilhaca comum permitirá maior rendimento de matéria seca e, consequentemente, maior quantidade de $\mathrm{N}$ fixada e posteriormente aportada ao sistema. Além disto, deve-se considerar que a taxa de crescimento da planta de ervilhaca é incrementada com o aumento da temperatura do ar. Em experimentos com época de dessecação e sistemas de manejo da ervilhaca comum, ARGENTA et al. (2000) e SILVA et al. (2001) verificaram que a sua dessecação 20 dias antes da semeadura do milho reduziu a quantidade de resíduos remanescentes na superfície do solo no dia da semeadura do milho em $67 \%$, quando comparada à realizada um dia antes da semeadura do milho (tabela 3). No entanto, neste estudo, a época de dessecação da ervilhaca comum não afetou o rendimento de grãos de milho, na média de dois níveis de $\mathrm{N}$ aplicado em cobertura (15 e $120 \mathrm{~kg} \mathrm{ha}^{-1}$ ), devido ao alto rendimento de matéria seca produzida por ocasião da dessecação da ervilhaca ( $>4 t \mathrm{tha}^{-1}$ ) que forneceu suficiente $\mathrm{N}$ para desenvolvimento adequado do milho. Outra prática cultural que poderá possibilitar maior tempo de permanência de resíduos de fabáceas na superfície do solo, é o uso de herbicidas recomendados para controle de plantas daninhas em pré-emergência do milho (mistura de atrazine e simazine) em substituição aos herbicidas não-seletivos no processo de dessecação destas espécies. Este manejo permitiria maior tempo de sobrevivência da planta de ervilhaca comum, além de auxiliar no controle de plantas daninhas no milho (ARGENTA et al., 2000). 
Tabela 3 - Atraso na época de dessecação da ervilhaca comum para aumentar o tempo de permanência de resíduos na superfície do solo para a cultura do milho em sucessão. Eldorado do Sul-RS, 2000/2001.

\begin{tabular}{|c|c|c|c|c|}
\hline \multirow{2}{*}{ Característica } & \multicolumn{4}{|c|}{ Épocas de dessecação da ervilhaca - DAS ${ }^{1 /}$} \\
\hline & 20 & 10 & 1 & Não dessecada \\
\hline $\mathrm{MS}^{2 /}$ da ervilhaca na dessecação ( $\mathrm{t}$ ha $\left.{ }^{-1}\right)$ & $4,1 \mathrm{a}^{*}$ & $4,2 \mathrm{a}$ & $4,4 \mathrm{a}$ & $4,5 \mathrm{a}$ \\
\hline MS da ervilhaca na semeadura do milho ( $\mathrm{ha}^{-1}$ ) & $2,67 \mathrm{~b}$ & $3,78 \mathrm{ab}$ & 4,39 a & 4,51 a \\
\hline $\mathrm{N}^{3 /}$ na ervilhaca na semeadura do milho ( $\left.\mathrm{kg} \mathrm{ha}^{-1}\right)$ & $86 \mathrm{~b}$ & $113 \mathrm{ab}$ & 131 a & 135 a \\
\hline Rendimento de grãos de milho $\left(\mathrm{t} \mathrm{ha}^{-1}\right)^{4 /}$ & $12,6 \mathrm{a}$ & $12,3 \mathrm{a}$ & $12,4 \mathrm{a}$ & $12,1 \mathrm{a}$ \\
\hline
\end{tabular}

${ }^{1 /}$ Dias antes da semeadura do milho; ${ }^{2 /}$ Matéria seca produzida; ${ }^{3 /}$ Nitrogênio acumulado; ${ }^{4 / N a}$ média de dois níveis de $\mathrm{N}$ aplicado em cobertura no milho (15 e $120 \mathrm{~kg} \mathrm{ha}^{-1}$ ); *Médias seguidas pela mesma letra na linha não diferem significativamente entre si pelo teste de Tukey ( $<<0,05$ ).

Fonte: ARGENTA et al. (2002).

\section{CONCLUSÕES}

Entre as estratégias que podem ser usadas para aumentar a eficiência de uso do nitrogênio (N) no milho cultivado em sucessão a espécies de cobertura de solo no inverno, destaca-se a utilização de práticas de manejo que possibilitem maior sincronia entre a época de aplicação de $\mathrm{N}$ e os estádios de maior demanda da planta.

$\mathrm{O}$ aumento da dose de $\mathrm{N}$ na semeadura, o atraso da época de semeadura do milho em sucessão à aveia preta e a utilização desta em consórcio com fabáceas ou brassicáceas são estratégias eficientes para reduzir os efeitos prejudiciais da aveia preta sobre o milho.

O rendimento de grãos de milho em sucessão a espécies fabáceas e brassicáceas como coberturas de solo no inverno, em cultivos isolados ou em consórcio com aveia preta, é maior do que o obtido em sucessão à aveia preta em cultivo isolado, especialmente em situações de baixo aporte de $\mathrm{N}$ em cobertura no milho, o que demonstra a contribuição destas espécies em disponibilizar $\mathrm{N}$ ao sistema.

\section{AGRADECIMENTOS}

Agradecimentos ao Conselho Nacional de Desenvolvimento Científico e Tecnológico pelas bolsas de produtividade e pesquisa do primeiro e terceiro autores, pela bolsa de mestrado do quarto autor e pela bolsa de iniciação científica do quinto autor.

\section{REFERÊNCIAS}

AITA, C. et al. Plantas de cobertura de solo como fonte de nitrogênio ao milho. Revista Brasileira de Ciência do Solo, Viçosa, v.25, p.157-165, 2001.

AITA, C.; GIACOMINI, S.J. Decomposição e liberação de nitrogênio de resíduos culturais de plantas de cobertura de solo solteiras e consorciadas. Revista Brasileira de Ciência do Solo, Viçosa, v.27, p.601-612, 2003.

AMADO, T.J.C. et al. Recomendação de adubação nitrogenada para o milho no RS e SC adaptada ao uso de culturas de cobertura de solo, sob sistema de plantio direto. Revista Brasileira de Ciência do Solo, Viçosa, v.26, p.241-248, 2002.

AMADO, T.J.C. et al. Culturas de cobertura, acúmulo de nitrogênio total no solo e produtividade de milho. Revista Brasileira de Ciência do Solo, Viçosa, v.23, p.679-686, 1999.

ARGENTA, G. et al. Efeitos de sistemas de manejo de ervilhaca comum sobre a cultura do milho semeada em sucessão. In: REUNIÃO TÉCNICA ANUAL DO MILHO, 45.; REUNIÃO TÉCNICA ANUAL DO SORGO, 28., 2000, Pelotas. Anais... Pelotas: Embrapa Clima Temperado, 2000. p.589-597.

ARGENTA, G. et al. Manejo do nitrogênio no milho em semeadura direta em sucessão a espécies de cobertura de solo no inverno e em dois locais. II - Efeitos sobre o rendimento de grãos. Ciência Rural, Santa Maria, v.29, n.4, p.587-593, 1999.

ARGENTA, G. et al. Efeitos do manejo mecânico e químico da aveia preta no milho em sucessão e no controle do capim papuã. Pesquisa Agropecuária Brasileira, Brasília, v.36, n.6, p.851-860, 2001.

ARGENTA, G. et al. Sistemas de cobertura de solo no inverno e seus efeitos sobre o rendimento de grãos de milho, em dois 
ambientes contrastantes. In: REUNIÃO TÉCNICA ANUAL DO MILHO, 47.; REUNIÃO TÉCNICA ANUAL DO SORGO, 30., 2002, Porto Alegre. Anais... Porto Alegre: FEPAGRO, 2002. CD-ROM

BARNI, N.A. et al. Plantas recicladoras de nutrientes e de proteção do solo, para uso em sistemas equilibrados de produção. Porto Alegre: FEPAGRO, 2003. 84p. (Boletim Fepagro, 12).

BAYER, C.; AMARAL, A.S. Amenização da acidez de um latossolo argiloso por extratos aquosos de planta de cobertura de inverno. Revista de Ciências Agroveterinárias, Lages, v.2, p.88-96, 2003

BOLINDER, M.A. et al. The response of soil quality indicators to conservation management. Canadian Journal Soil Science, Ottawa, v.79, p.37-45, 1999.

BORKERT, C.M. et al. Nutrientes minerais na biomassa da parte aérea em culturas de cobertura de solo. Pesquisa Agropecuária Brasileira, Brasília, v.38, n.1, p.143-153, 2003.

BORTOLINI, C.G. et al. Sistemas consorciados de aveia preta e ervilhaca comum como cobertura de solo e seus efeitos na cultura do milho em sucessão. Revista Brasileira de Ciência do Solo, Viçosa, v.24, p.897-903, 2000.

BORTOLINI, C.G. et al. Rendimento de grãos de milho cultivado após aveia preta em resposta a adubação nitrogenada e regime hídrico. Pesquisa Agropecuária Brasileira, Brasília, v.36, n.9, p.1101-1106, 2001.

BURLE, M.L. et al. Effect of cropping systems on soil chemical characteristics, with emphasis on soil acidification. Plant and Soil, Dordrecht, v.190, p.309-316, 1997.

CERETTA, C.A. et al. Manejo da adubação nitrogenada na sucessão aveia preta/milho, no sistema plantio direto. Revista Brasileira de Ciência do Solo, Viçosa, v.26, p.163-171, 2002.

EMBRAPA. Plataforma plantio direto. 2003. Capturado em 12 out. 2004. Online. Disponível na Internet: http:// www.embrapa.br/plantiodireto/introducaohistorico/ sistemaplantiodireto.htm

EMBRAPA. Vantagens do plantio direto são apresentadas na Expointer 2004. 2005. Capturado em 02 ago. 2005. Online. Disponível na Internet: http://www.cnpt.embrapa.br/ noticias/not0489.htm

FARIAS, A.D.; FERREIRA, T.N. Sistema de plantio direto no Rio Grande do Sul. Informativo da EMATER/RS, Porto Alegre v.18, n.7, p.??, 2000

FORSTHOFER, E.L. Desempenho agronômico e econômico do milho em diferentes níveis de manejo e épocas de semeadura. 2004. 95f. Dissertação (Mestrado em Fitotecnia) - Programa de Pós-graduação em Fitotecnia, Faculdade de Agronomia, Universidade Federal do Rio Grande do Sul.

FORSTHOFER, E.L. et al. Avaliação do potencial de rendimento de grãos de milho em função de níveis de manejo em três épocas de semeadura. In: REUNIÃO TÉCNICA CATARINENSE DE MILHO E FEIJÃO, 4.; REUNIÃO SULBRASILEIRA DE FEIJÃO, 6., 2003, Lages. Resumos Expandidos... Lages: UDESC/EPAGRI, 2003. p.95-100.

FRANCHINI, J.C. et al. Rapid transformations of plant watersoluble compounds in relation to cation mobilization in an acid oxisol. Plant and Soil, Dordrecht, v.231, p.55-63, 2001.

GIACOMINI, S.J. et al. Consorciação de plantas de cobertura antecedendo o milho em plantio direto. II - Nitrogênio acumulado pelo milho e produtividade de grãos. Revista Brasileira de Ciência do Solo, v.28, p.751-762, 2004.

MATZENAUER, R. et al. Consumo de água e disponibilidade hídrica para milho e soja no Rio Grande do Sul. Porto Alegre: FEPAGRO, 2002. 105p. (Boletim FEPAGRO, 10).

MONEGAT, C. Plantas de cobertura do solo: características e manejo em pequenas propriedades. Chapecó, SC.: Ed. do Autor, 1991. 337p.

MOODY, J.E. et al. Growing corn without tillage. Soil Science Society of America Journal, Madison, v.6, n.5, p.516-517, 1961.

PÖTTKER, D.; WIETHÖLTER, S. Épocas e métodos de aplicação de nitrogênio em milho cultivado no sistema plantio direto. Ciência Rural, Santa Maria, v.34, n.4, p.1015-1020, 2004.

REGO, P.G. Economia das rotações de culturas em plantio direto. Revista Mensal Batavo, Castro, ed.31, p.20-28, 1994.

REUNIÃO TÉCNICA DE PESQUISA DE MILHO E SORGO DO RS (50 e 33), Indicações técnicas para cultivo de milho e sorgo no Rio Grande do Sul 2005/2006. Porto Alegre, 2005. $155 p$.

SÁ, J.C.M. de. Efeito de doses e época de aplicação de nitrogênio na produção de milho, após resteva de aveia-preta (Avena strigosa), sob plantio direto. In: FUNDAÇÃO ABC. Resultados de Pesquisa 88/89. Castro: FUNDAÇÃO ABC, 1989. 61p. (Boletim Técnico, 4).

SÁ, J.C.M. de. Manejo de nitrogênio na cultura do milho no sistema de plantio direto. Passo Fundo: Aldeia Norte, 1996. 24p

SANTOS, H.P. dos; REIS, E.M. Rotação de culturas em plantio direto. Passo Fundo: Embrapa Trigo, 2001. 212 p.

SILVA, P.R.F. da. et al. Época de dessecação da ervilhaca comum e seus efeitos sobre a cultura do milho em sucessão. In: REUNIÃO ANUAL DO MILHO, 46; REUNIÃO ANUAL DO SORGO, 29., 2001, Porto Alegre. Anais... Porto Alegre: FEPAGRO, 2001. CD-ROM.

SUHRE, E. et al. Sistemas de cobertura de solo no inverno e seus efeitos sobre o rendimento de grãos de milho implantado em sucessão. In: CONGRESSO NACIONAL DE MILHO E SORGO, 25., 2004, Cuiabá. Resumos Expandidos... Sete Lagoas: ABMS/EMBRAPA MILHO E SORGO/EPAGRI, 2004. CD-ROM. 
TISDALL, J.M.; OADES, J.M. Organic matter and waterstable aggregates in soils. Journal of Soil Science, Oxford, v.33, p.141-163, 1982.

VARGAS, L.K. et al. Imobilização de nitrogênio em solo cultivado com milho em sucessão à aveia preta nos sistemas plantio direto e convencional. Ciência Rural, Santa Maria, v.35, n.1, p.76-83, 2005.
VEZZANI, F.M. Qualidade no sistema solo na produção agrícola. 2002. 107f. Tese (Doutorado em Ciência do Solo)

- Programa de Pós-graduação em Ciência do Solo, Faculdade de Agronomia, Universidade Federal do Rio Grande do Sul.

VICTORIA, R.L. et al. O ciclo do nitrogênio. In: CARDOSO, E.J.B.N. et al. (Coord). Microbiologia do solo. Campinas: Sociedade Brasileira de Ciência do Solo, 1992. p.105-120. 